\title{
High risk feet in subacute rehabilitation facilities: how many are there?
}

\author{
Brenton J Earl ${ }^{1,2^{*}}$, Peter A Lazzarini ${ }^{2,3,4}$, Ewan M Kinnear ${ }^{2}$, Petrea L Cornwell ${ }^{3,5}$ \\ From Australasian Podiatry Council Conference 2013 \\ Sydney, Australia. 2-5 June 2013
}

\section{Background}

Australian subacute rehabilitation facilities face significant challenges from the ageing population with increased burden of chronic disease. High risk foot complications are a negative consequence of many chronic diseases. With the rapid expansion of subacute services, it seems imperative to investigate the prevalence of foot complications in this population. The primary aim of this study was to quantify the high risk foot complication prevalence in a subacute rehabilitation population.

\section{Methods}

Eligible participants were all adults admitted overnight, over two 4 week periods, into a large Australian subacute rehabilitation facility. Consenting participants underwent a short non-invasive foot examination by a podiatrist. The standard Queensland Health High Risk Foot Form collected data on age, sex, co-morbidities and foot complications. Descriptive statistics, logistic regression and odds ratios were used to determine the prevalence of foot complications and associations with explanatory variables.

\section{Results}

Overall, 85 of 97 eligible participants consented; mean age $80(9)$ and $71 \%$ were female. At least one foot complication was present in $56.5 \%$ participants; including $21.2 \%$ defined as high risk and $11.8 \%$ current foot ulcer. A previous diagnosis of neuropathy increased the risk of presenting with a high risk foot by 13 -fold (OR 13.504, $\mathrm{p}=0.001)$.

\section{Conclusion}

This study highlights the significance of foot complications in the subacute population. It appears that one in every two patients present with a foot complication and one in eight with a foot ulcer. It is suggested all patients admitted to subacute rehabilitation services should be screened for foot complications.

\section{Author details \\ ${ }^{1}$ Brighton Health Campus \& Services, Metro North Hospital and Health Service, Queensland Health, Brisbane, Queensland, 4017, Australia. ${ }^{2}$ Department of Podiatry, Metro North Hospital and Health Service, Queensland Health, Brisbane, Queensland, 4032, Australia. ${ }^{3}$ Allied Health Research Collaborative, Metro North Hospital and Health Service, Queensland Health, Brisbane, Queensland, 4032, Australia. ${ }^{4}$ School of Clinical Sciences, Queensland University of Technology, Brisbane, Queensland, 4059, Australia. ${ }^{5}$ Behavioural Basis of Health, Griffith Health Institute, Griffith University, Brisbane, Queensland, 4122, Australia.}

Published: 31 May 2013

\section{doi:10.1186/1757-1146-6-S1-O11}

Cite this article as: Earl et al:: High risk feet in subacute rehabilitation facilities: how many are there? Journal of Foot and Ankle Research 2013 6(Suppl 1):011.

Submit your next manuscript to BioMed Central and take full advantage of:

- Convenient online submission

- Thorough peer review

- No space constraints or color figure charges

- Immediate publication on acceptance

- Inclusion in PubMed, CAS, Scopus and Google Scholar

- Research which is freely available for redistribution
* Correspondence: brenton.earl@health.qld.gov.au
'Brighton Health Campus \& Services, Metro North Hospital and Health

Service, Queensland Health, Brisbane, Queensland, 4017, Australia

Full list of author information is available at the end of the article 